\title{
COASTAL FLOODING RISK CALCULATIONS FOR THE BELGIAN COAST
}

Verwaest, T. ${ }^{1}$, Van der Biest, K. ${ }^{1}$, Vanpoucke, P. ${ }^{2}$, Reyns, J. ${ }^{2}$, Vanderkimpen, P. ${ }^{3}$, De Vos, L. ${ }^{2}$, De Rouck, J. ${ }^{2}$, Mertens, T. ${ }^{4}$

This paper details the methodology which is used to perform a flood risk analysis for the Belgian coast. The coastal flood risk analysis aims at estimating the expected value of yearly consequences by coastal flooding for a given time horizon. To calculate the risk all sources of uncertainty are accounted for by using a pragmatic probabilistic method. To calculate the flood consequences for a given extreme storm surge, a chain of process models is used that describe the wave propagation towards the coast, the failure behaviour of the coastal defences, the flooding of the coastal plain and the resulting consequences (economic damage and human casualties).

\section{INTRODUCTION}

\section{The Belgian coastal zone}

Belgium is situated at the shores of the Southern North Sea. The length of the Belgian coastline is approximately $67 \mathrm{~km}$. The flood prone low-lying coastal area has an average width of $15 \mathrm{~km}$ and is located on average $2 \mathrm{~m}$ below the surge level of an annual storm (Fig. 1). The natural coastal defences are sandy beaches and dunes, which have been strengthened by revetments in the coastal towns. In the central part of the coast, between Nieuwpoort and Zeebrugge (Fig. 1), the width of the coastal defences is limited, through which breaching may occur. In the coastal harbours structures such as quays, dikes and sluices function as a part of the coastal defence system. At several locations the height or the strength of these harbour structures is limited, resulting into breaching possibilities via the harbours.

\footnotetext{
${ }^{1}$ Flanders Hydraulics Research, Berchemlei 115, 2140 Antwerp, Belgium, toon.verwaest@mow.vlaanderen.be

2 University of Ghent, Technologiepark Zwijnaarde 904, 9052 Zwijnaarde, Belgium

${ }^{3}$ Soresma - Haecon nv, Poortakkerstraat 41, 9051 Gent, Belgium

${ }^{4}$ Flanders Coastal Services - MDK, Vrijhavenstraat 3, 8400 Oostende, Belgium
} 


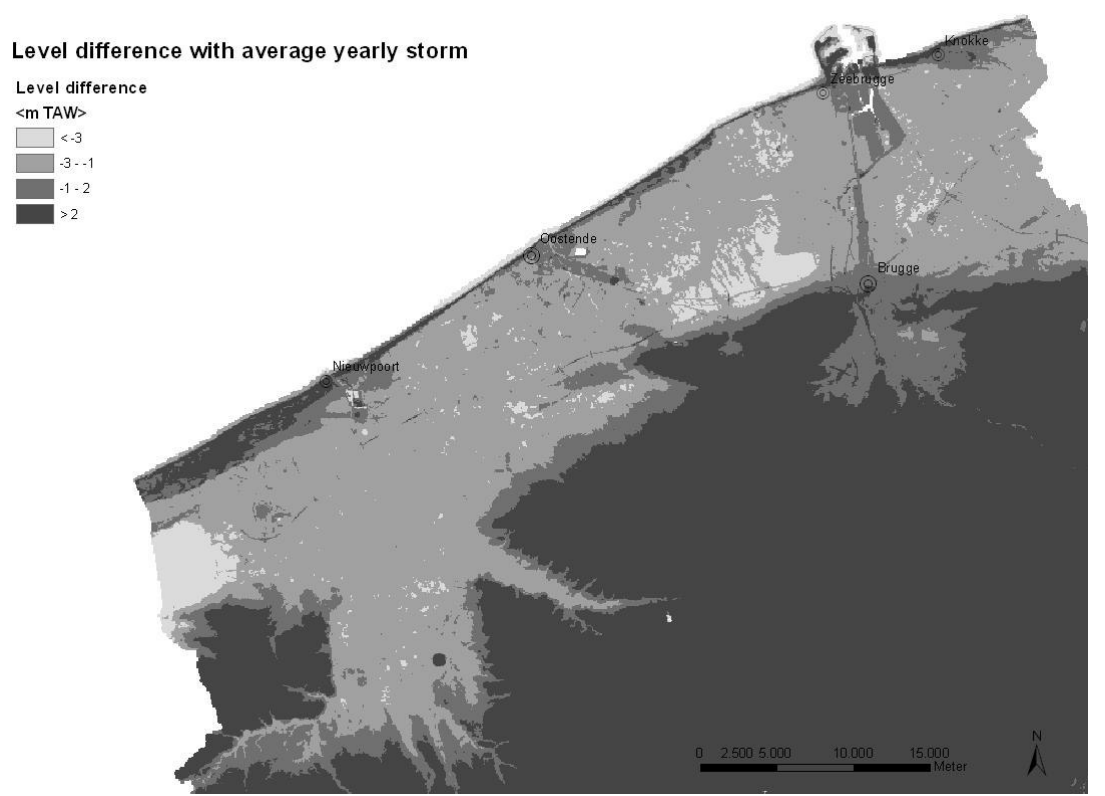

Figure 1. Level difference between the coastal land and the surge level of an annual storm (the height of the land is accurately known from airborne laser altimetry).

\section{Coastal flooding risks at the Belgian coast}

Flooding is very unlikely in the Belgian coastal zone, but the consequences can be dramatic. The present coastal defence system can withstand a 100 years storm surge. In case of failure however, hundreds of thousands of people and tens of billions of euros in assets are threatened. The most recent flooding in the Belgian coastal zone occurred in 1953, together with dramatic floodings in the Netherlands and the United Kingdom that caused thousands of human casualties, not to mention the enormous economic damages.

The Belgian standard of coastal protection aims for safety against a surge level with a return period of 1000 years, but at present it is investigated if and how this standard could be redefined based on risk analysis. From an economic point of view it is optimal to give more protection to areas where the values to be protected are larger, given that the budget for investments in coastal protection is limited. From a societal perspective however, a minimum safety level is to be guaranteed for everybody living in the coastal zone.

Almost 10 years ago the first studies were performed regarding Belgian coastal flooding risks. At present first results are available for the whole area. 


\section{FLOOD RISK ANALYSIS METHODOLOGY}

\section{The general risk formula}

A coastal flood risk analysis aims at estimating the expected value of yearly negative consequences by coastal flooding for a given time horizon. To calculate the risk one has to distinguish different sources of uncertainty, and weigh the consequences and probabilities that are associated. So by definition:

$$
\text { risk }=\sum(\text { probabilities } \times \text { consequences })
$$

We distinguish four different sources of uncertainty (Verwaest et al 2007):

1. The unpredictability of the weather.

2. The uncertainty on the extreme value probability distribution of extreme storm surge events.

3. The limited knowledge of the state of the coastal defence system and of its behaviour during the considered storm conditions. Uncertainty analysis showed that the chain of models to calculate flood damage from storm surge characteristics is most sensitive to the uncertainty on the number of breaches in the coastal defence system. The uncertainty on the failure behaviour of the coastal defences outweighs the uncertainties associated with wave propagation modeling, hydraulic modeling and modeling of damages.

4. Unknown future values of economic growth rate, population growth rate, sea level rise rate and discount rate, for the time horizon under consideration.

A pragmatic probabilistic method is developed to account for all four above mentioned independent sources of uncertainty, namely by using the general risk formula:

$$
r i s k=\left[\sum_{i, j, k} p_{j} \cdot p_{k} \cdot\left(\frac{w_{i}}{R_{i}}\right)_{j} \cdot S_{i, k}\right] \cdot \frac{(1+r)^{T}-1}{r T}
$$

In Eq. $2 \sum_{i, j, k}$ is a weighted summation over three sources of uncertainty, represented by the three indices $i, j, k$, respectively the unpredictability of the weather (index $i$ ), the uncertainty on the extreme value distribution of surge levels (index $j$ ) and the uncertainty on the coastal defence system (index $k$ ). A series of possible storm surges is considered (index $i$ ), e.g. $+2 \mathrm{~m}(\mathrm{i}=1) ;+2,5 \mathrm{~m}$

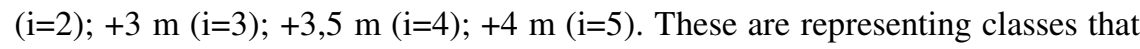
contain all possible storms. From earlier studies it is known that the surge level is the most important storm characteristic for the impact on the coastal defences. Other characteristics such as wave heights and storm duration are therefore 
treated as dependent of the surge level. Each storm surge is given a weight equal to the probability of occurrence of its class. This is calculated as a weighted average namely $\sum_{j} p_{j} \cdot\left(\frac{w_{i}}{R_{i}}\right)_{j}$ taking into account the wide spectrum of possible extreme value distributions for the surge level (index $j$ ). For each storm surge the damages $S_{i, k}$ are also dependent on the model used for describing the behaviour of the coastal defence system (index $k$ ). Apart from a best estimate "central" model, more conservative or more optimistic models are constructed. By definition the "central" models have a $50 \%$ probability of underestimating and have a $50 \%$ probability of overestimating. The "off-central" models are constructed to give results with a fixed off-set, e.g. a "+ sigma" model gives results with by definition a $16 \%$ probability of underestimating and a $84 \%$ probability of overestimating. The "off-central" models are constructed as variations of the "central" model. For a given storm surge the different damage results are then calculated as a weighted average namely $\sum_{k} p_{k} \cdot S_{i, k}$, averaging over e.g. 5 models: the "central" model $(\mathrm{k}=0)$; the "+sigma" model $(\mathrm{k}=+1)$; the "-sigma" model $(\mathrm{k}=-1)$; the " +2 sigma" model $(\mathrm{k}=+2)$; the "-2 sigma" model $(\mathrm{k}=-2)$. The so-called "rate-factor" $\frac{(1+r)^{T}-1}{r T}$ takes into account the effect of the trends of some external conditions such as sea level rise and economic growth by combining the yearly rates of change $r$ (\%/year) and the time horizon $T$ that is considered. From sensitivity analysis it was found that if one takes a time horizon of less than 50 years the uncertainty on future developments (sea level rise, societal evolution...) is small compared to the other sources of uncertainty. However, uncertainty on future developments becomes a dominating source of uncertainty if one takes a time horizon of more than 100 years (Verwaest et al 2008). In our study we take a time horizon of a few decades, namely until 2050, which means that the rate-factor has only a small effect of the order of $\pm 10 \%$ on the risk.

\section{The occurrence probability of storm surges}

An extreme value analysis of coastal high water levels has been performed in which special attention was given to the uncertainty around the extreme value distribution caused by the limited amount of data. The dataset used is a time series of 76 years (1925-2000) of high water levels along the Belgian coast at Ostend. Parametric bootstrapping allowed the confidence limits on the extreme value distributions to be quantified. Uncertainties on extreme value distributions are found to be very large (Fig. 2) (Willems and Verwaest 2008). 


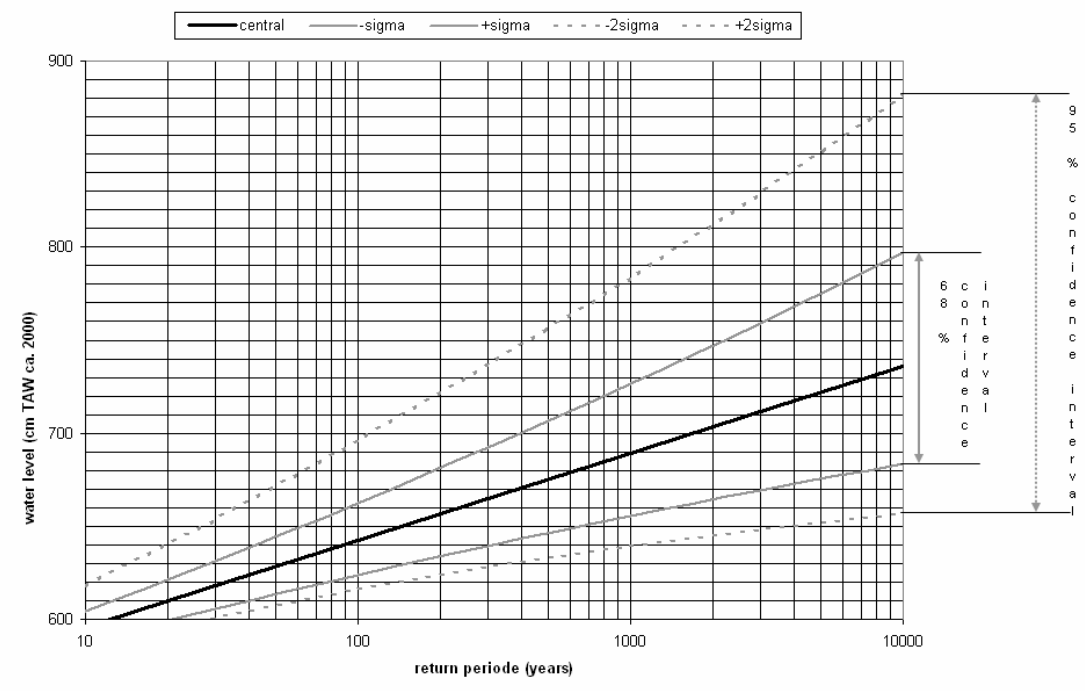

Figure 2. Extreme value probability distribution for surge levels (based on high water measurements at Ostend, Belgium). The figure shows the "central" curve and also 4 "off-central" curves that indicate the $68 \%$ confidence interval (" \pm sigma") and the $95 \%$ confidence interval (" \pm 2 sigma”).

It is important to take this uncertainty regarding the extreme value probabilities of surge levels into account in coastal design applications. As explained before, in the coastal flooding risk calculations we do take this into consideration in a pragmatic way by weighted averaging. We found that the risk results are significantly higher compared to what we should have found by only using the central curve. Because the uncertainty increases for higher surge levels, the effect on the risks increases as well. To illustrate the importance of the effect, numbers are given as multiplication factors in Table 1 .

\begin{tabular}{|c|c|}
\hline \multicolumn{2}{|c|}{ Table 1. Multiplication factor for increasing surge levels. } \\
\hline \begin{tabular}{c|} 
Surge height above \\
high water
\end{tabular} & Multiplication factor (the ratio of the risk results compared to \\
& what we would have calculated by only using the central curve) \\
\hline$+2 \mathrm{~m}$ & 1,1 \\
$+2,5 \mathrm{~m}$ & 1,5 \\
$+3 \mathrm{~m}$ & 3 \\
$+3,5 \mathrm{~m}$ & 5 \\
$+4 \mathrm{~m}$ & 25 \\
\hline
\end{tabular}

If one would improve the accuracy of the extreme value distribution of surge levels and the central model would not change, the flooding risk would decrease with a factor depending on the value of the lowest surge that causes significant flooding (see Table 1). 


\section{The consequences of storm surges}

To calculate the flood damage for a given extreme storm surge, a chain of process models is used describing the wave propagation towards the coast, the failure behaviour of the coastal defences, the flooding of the coastal plain and the resulting consequences (economic damage, human casualties,...). In this paper emphasis is on the modeling of failure behaviour of the defences, because this part of the chain of models is most sensitive. The response of the coastal defence system is simulated as a combination of wave propagation towards the coastal defence, beach erosion, wave overtopping, structural failure of the revetment, erosion of the core and finally breach growth. Wave propagation is modeled with the freely available software SWAN (http://www.fluidmechanics.tudelft.nl/swan/). Beach erosion is modeled with the process model DUROSTA (Steetzel 1993). Wave overtopping is modeled using the state of the art given in the EurOtop manual (www.overtoppingmanual.com). The same reference is used to assess the critical overtopping discharge resulting in structural failure of the revetment. Landward erosion of the core and breach growth is modeled using parameterisations (respectively Visser 2002 adapted for overtopping by Kortenhaus 2003, and Verheij 2002). Flooding simulations are performed with the commercial software MIKE21. Finally, economical damage and potential human casualties are calculated using damage functions developed by Flanders Hydraulics Research and Ghent University for the Flemish region (Vanneuville et al 2003).

Some illustrations of these calculations are given below. Fig. 3 shows the typical result of a combined calculation of beach erosion in front of a sea dike, wave impact on the dike and wave overtopping over the dike. Fig. 4 illustrates the erosion calculation of the core of a sea dike with the Visser-Kortenhaus model. 


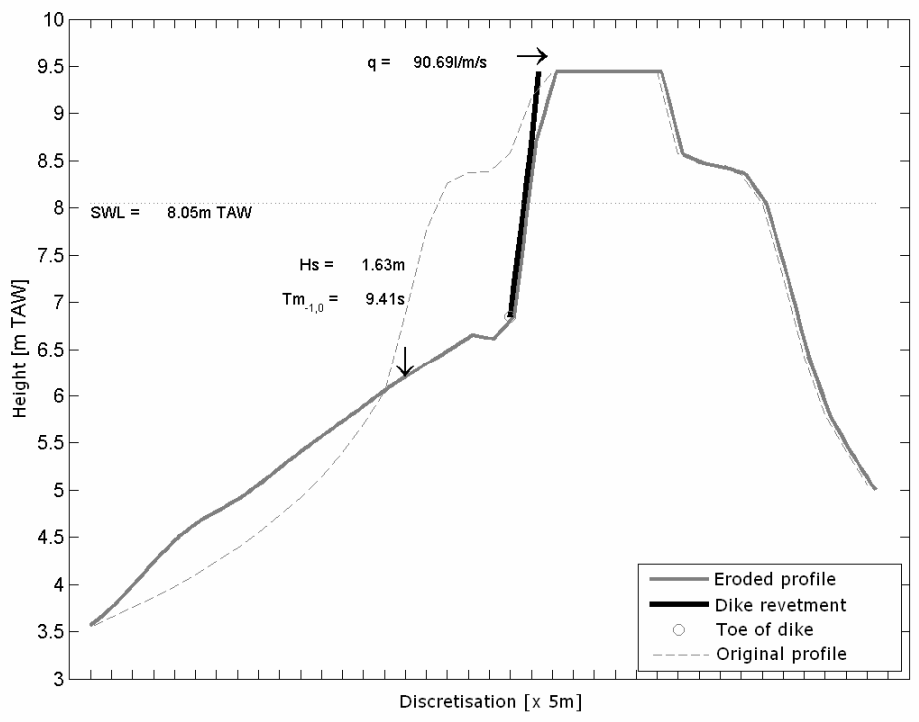

Figure 3. Example result of a combined calculation of beach erosion in front of a sea dike, wave impact on the dike and wave overtopping over the dike.
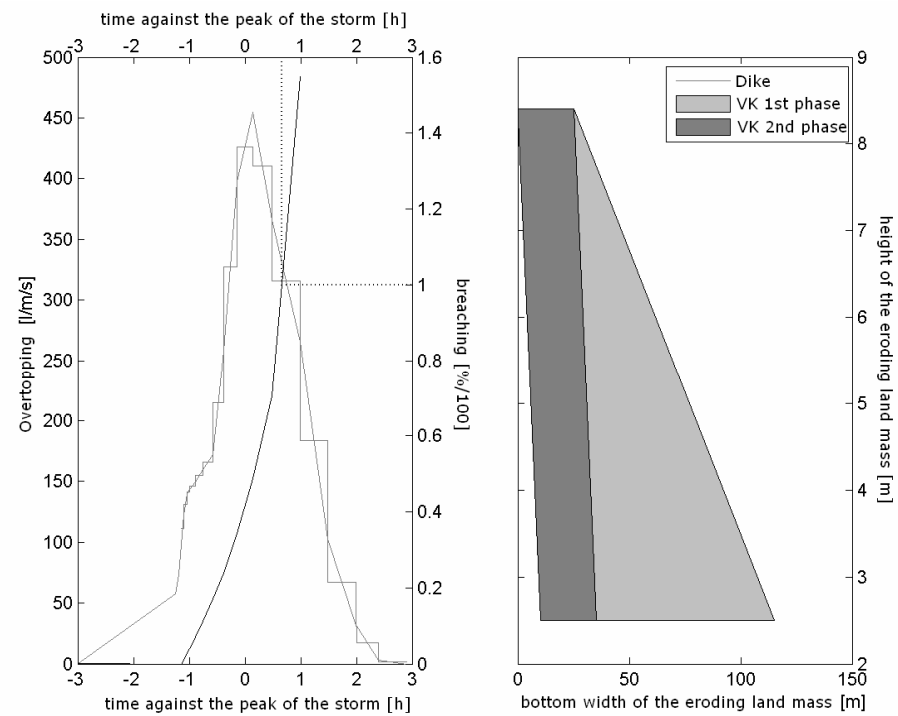

Figure 4. Example result of a Visser-Kortenhaus calculation describing the erosion of the core of a sea dike. In this example the erosion starts when the overtopping is larger than the critical value of $100 \mathrm{liter} / \mathrm{s} / \mathrm{m}$ and a breach is formed ca. $1 / 2$ hour later. 
As explained before we construct also "off-central" models for describing the failure behaviour of the coastal defences. A very pragmatic procedure is followed, because using classical probabilistic approaches such as Monte Carlo analysis is not feasible within the project (too many calculations would be needed). First an uncertainty analysis is carried out to determine the dominating sources of uncertainty in the failure models. All other sources of uncertainty can be neglected. For example, it was found from an uncertainty analysis regarding the beach erosion modeling with DUROSTA that the most dominating source of uncertainty is the model uncertainty. Based on comparisons between calculations with DUROSTA and experiments in a wave flume a standard deviation of $40 \%$ was found regarding the erosion volume. Based on the results of the uncertainty analyses the "off-central" models are then constructed using expert judgment, meaning that a consensus is sought between the different experts that participate in the study. For example, for the DUROSTA beach erosion modeling the "+ sigma" model was decided to be a variation of the central model where the grain size is reduced with $30 \%$. We found that the risk results are significantly higher compared to what we should have found by only using the "central" model. As can be expected the importance of this effect is very case-specific. As an example, numbers are given as multiplication factors in Table 2 for one of the weak links in the coastal defences (a sea dike in Ostend), for different elements of the failure modeling.

\begin{tabular}{|l|l|}
\hline $\begin{array}{l}\text { Table 2. Multiplication factor for different parts of the failure modeling, for the } \\
\text { case of the sea dike in Raversijde-Mariakerke-Oostende. }\end{array}$ \\
\hline $\begin{array}{l}\text { Part of the failure modeling for which an "off-central" } \\
\text { model is constructed }\end{array}$ & $\begin{array}{l}\text { Multiplication factor (the ratio } \\
\text { of the risk result using the } \\
\text { "+sigma" model compared to } \\
\text { the risk result using the } \\
\text { central model) }\end{array}$ \\
\hline \multicolumn{2}{|c|}{1,3} \\
DUROSTA beach erosion. \\
Overtopping formula \& critical overtopping discharge. \\
Visser-Kortenhaus erosion of the core. \\
\hline
\end{tabular}

If one would improve the accuracy of the failure models and the central model would not change, the flooding risk would decrease with a factor that depends on the relative importance of the different submodels.

\section{CONCLUSIONS}

A flood risk analysis for the Belgian Coast is presented. The results of this analysis will be a basis for the integrated master plan for coastal defence in Belgium (Mertens et al 2008). 
Research is recommended on the failure behaviour of the coastal defences and on the extreme value statistics of storm surges, because these dominate the uncertainty on the present risk calculations.

\section{REFERENCES}

Kortenhaus. 2003. Probabilistische Methoden für Nordseedeiche, PhD, Leichtweiß-Institut für Wasserbau, Technische Universität Braunschweig.

Mertens, De Wolf, Verwaest, Trouw, De Nocker, Couderé. 2008. An integrated master plan for Flanders future coastal safety, Proceedings of $31^{\text {st }}$ International Conference on Coastal Engineering, ASCE (this publication).

Steetzel. 1993. Cross-shore transport during storm surges, $\mathrm{PhD}$, TU Delft.

Vanneuville, De Maeyer, Maeghe, Mostaert. 2003. Model of the effects of a flood in the Dender catchment based on a risk methodology. SoC BULLETIN, Vol. 37, No 2, pp 59-64.

Verheij. 2002. Modification breach growth model in HIS-OM, WLDelft Hydraulics, report Q3299.

Verwaest, Vanneuville, Peeters, Mertens, De Wolf. 2007. Uncertainty on coastal flood risk calculations, and how to deal with it in coastal management. Case of the Belgian coastal zone, 2nd IMA international conference on flood risk assessment, 4-5 September 2007, university of Plymouth, UK.

Verwaest, Van Poucke, Reyns, Van der Biest, Vanderkimpen, Peeters, Kellens, Vanneuville. 2008. SAFECoast: comparison between different flood risk methodologies: action $3 B$ report, SAFECoast Interreg IIIb North Sea project, Flanders Hydraulics Research, Belgium.

Visser. 2002. Breach growth in sand-dikes, PhD, TU Delft.

Willems and Verwaest. 2008. Extreme value analysis of coastal levels, with and without convolution of astronomic and storm surge components, Proceedings of $31^{\text {st }}$ International Conference on Coastal Engineering, ASCE (this publication). 